\title{
Florence Nightingale, la vigencia de un legado
}

Florence Nightingale, the validity of a legacy

https://doi.org/10.37135/ee.04.11.01

Autor:

Daniel Ernesto Gutiérrez Raina ${ }^{1}$ - https://orcid.org/0000-0001-6832-2960

${ }^{1}$ Universidad Adventista del Plata, Argentina.

Autor de correspondencia: Universidad Adventista del Plata, Argentina. Teléfono: (0343) 155039325. Email: gutierrezrainadanie155@gmail.com.

\section{RESUMEN}

El legado de Florence Nightingale mantiene su vigencia, reflejándose en cada profesional de la Enfermería contemporáneo que desarrolla su labor en los diversos niveles de atención, realizando disímiles cuidados de salud.

Palabras clave: historia de la enfermería, proceso de enfermería, ciencia.

\section{ABSTRACT}

Florence Nightingale's legacy remains valid, being reflected in each contemporary Nursing professional who develops his/her work at various levels of care, performing dissimilar healthcare.

Keywords: History of Nursing, Nursing Process, Science.

Estimado Editor de la Revista Eugenio Espejo:

En el siglo XXI, el legado de Florence Nightingale vive en cada una de las enfermeras y enfermeros que continúa cuidando de la salud de las personas en todos los niveles de atención y contextos de cuidado posibles, procurando cumplir la meta de una cobertura sanitaria universal. ${ }^{(1)}$

Nightingale estaría orgullosa de ver como la Enfermería evolucionó hasta convertirse en una ciencia con un sistema de teorías y modelos, con una práctica sistematizada, racional y fundamentada implementada mediante un proceso propio para la atención mediante el cuidado. ${ }^{(2)}$ 
El profesional de la Enfermería contemporáneo integra ciencia, comunicación, cultura y cuidado como vía para llegar hasta cada individuo, familia y comunidad independientemente de sus costumbres, tradiciones, sistemas de conocimientos, antecedentes históricos, etc. Lo que requiere de una formación transcultural, humanística y científica universal. ${ }^{(3)}$

Así, tal y como fuera en otras muchas epidemias, las herederas y herederos de Nightingale enfrentaron la pandemia de Covid-19 con abnegación, dedicación, desinterés, humanización del cuidado, paciencia, vocación, empatía, compromiso social y profesionalismo, entre otras muchas cualidades que ameritan ser destacadas por la comunidad científica en salud. ${ }^{(4)}$

Conflictos de intereses: el autor declara que no existen.

\section{Declaración de contribución:}

Daniel Ernesto Gutiérrez Raina realizó el análisis y la redacción del artículo científico.

\section{REFERENCIAS BIBLIOGRÁFICAS}

1. Castañeda-Hernández MA. Los Objetivos de Desarrollo Sostenible y sus vínculos con la profesión de enfermería. Rev Enferm IMSS [Internet]. 2017 [citado 21 Ene 2021]; 25(3): 161-162. Disponible en: https://www.medigraphic.com/pdfs/enfermeriaimss/eim-2017/ eim173a.pdf.

2. León-Román CA. Nuevas teorías en enfermería y las precedentes de importancia histórica. Rev Cubana Enferm [Internet]. 2017 [citado 23 Ene 2021]; 33(4). Disponible en: http://www.revenfermeria.sld.cu/index.php/enf/article/view/1587.

3. Escobar-Castellanos B, Paravic-Klijn T. La transculturalidad, elemento esencial para mejorar la atención en salud y de enfermería. Enfermería Actual de Costa Rica [Internet]. 2017 [citado 19 Ene 2021]; (33): 73-87. Disponible en: http://www.scielo.sa.cr/scielo.php ?script=sci_arttext\&pid=S1409-45682017000200073\&lng=en. http://dx.doi.org/10.15517/revenf.v0i33.29627.

4. Ortiz-Nievas VT. Reflexionando sobre la profesión de Enfermería en tiempos de pandemia Covid-19. BIC [Internet]. 2020 [citado 26 de enero de 2021]; 7(3). Disponible en: http://editorial.umariana.edu.co/revistas/index.php/BoletinInformativoCEI/article/view/ 2380 .

Recibido: 10 de noviembre de 2020

Aprobado: 12 de febrero de 2021 